\title{
Hippocampal Inactivation Disrupts the Acquisition and Contextual Encoding of Fear Extinction
}

\author{
Kevin A. Corcoran, ${ }^{1}$ Timothy J. Desmond, ${ }^{2}$ Kirk A. Frey, ${ }^{2,3}$ and Stephen Maren ${ }^{1,3}$ \\ ${ }^{1}$ Department of Psychology, University of Michigan, Ann Arbor, Michigan 48109-1043, 2Departments of Radiology and Neurology, University of Michigan, \\ Ann Arbor, Michigan 48109-0720, and ${ }^{3}$ Neuroscience Program, University of Michigan, Ann Arbor, Michigan 48109-0520
}

In recent studies, inactivation of the dorsal hippocampus before the retrieval of extinguished fear memories disrupted the contextdependent expression of these memories. In the present experiments, we examined the role of the dorsal hippocampus in the acquisition of extinction. After pairing an auditory conditional stimulus (CS) with an aversive footshock [unconditional stimulus (US)], rats received an extinction session in which the CS was presented without the US. In experiment 1, infusion of muscimol, a GABA $\mathrm{A}_{\mathrm{A}}$ receptor agonist, into the dorsal hippocampus before the extinction training session decreased the rate of extinction. Moreover, when later tested for fear to the extinguished CS, all rats that had received hippocampal inactivation before extinction training demonstrated renewed fear regardless of the context in which testing took place. This suggests a role for the dorsal hippocampus in both acquiring the extinction memory and encoding the CS-context relationship that yields the context dependence of extinction. In experiment 2, inactivation of the dorsal hippocampus before testing also disrupted the context dependence of fear to the extinguished CS. In experiment 3, quantitative autoradiography revealed the boundaries of muscimol diffusion after infusion into the dorsal hippocampus. Together, these results reveal that the dorsal hippocampus is involved in the acquisition, contextual encoding, and context-dependent retrieval of fear extinction. Learning and remembering when and where aversive events occur is essential for adaptive emotional regulation.

Key words: fear conditioning; extinction; hippocampus; context; muscimol; autoradiography

\section{Introduction}

In pavlovian fear conditioning, an auditory conditional stimulus (CS) is paired with an aversive unconditional stimulus (US). After fear conditioning, repeated presentations of the CS in the absence of the US (i.e., extinction training) results in reduced probability and amplitude (i.e., extinction) of the conditioned response (Pavlov, 1927). During later testing, retrieval of the extinction memory is contingent on presenting the CS in the context in which extinction training occurred; outside this context, renewal of fear is observed. This effect has been repeatedly demonstrated in both rats (Bouton and Bolles, 1979; Bouton and Ricker, 1994; Rauhut et al., 2001) and humans (Mineka et al., 1999; Mystkowski et al., 2002). In keeping with well established roles for the hippocampus in forming representations of contexts (Selden et al., 1991; Kim and Fanselow, 1992; Phillips and LeDoux, 1992; Matus-Amat et al., 2004), and using those representations to guide behavior (Frankland et al., 1998; Fanselow, 2000; Maren and Holt, 2000; Rudy and O’Reilly, 2001), mounting evidence suggests a role for the hippocampus in mediating the

Received Feb. 24, 2005; revised Aug. 15, 2005; accepted Aug. 15, 2005.

This research was supported by National Institute of Mental Health Grant R01MH065961 (S.M.) and a National Science Foundation Graduate Research Fellowship (K.A.C.). We thank Mary Beth Harris and Omry Maoz for technical assistance.

Correspondence should be addressed to Stephen Maren, Department of Psychology, University of Michigan, 530 Church Street, Ann Arbor, MI 48109-1043. E-mail: maren@umich.edu.

K. A. Corcoran's present address: Department of Physiology, Ponce School of Medicine, P.0. Box 7004, Ponce, Puerto Rico 00732-7004.

DOI:10.1523/JNEUROSCI.2246-05.2005

Copyright $\odot 2005$ Society for Neuroscience $\quad$ 0270-6474/05/258978-10\$15.00/0 context-specific retrieval of fear extinction (Corcoran and Maren, 2001, 2004).

The hippocampus plays an additional role in using contextual cues during the encoding of memory (Hirsh, 1974; Honey and Good, 1993; Freeman et al., 1996; Good et al., 1998; Kennedy and Shapiro, 2004; Smith et al., 2004). Although involvement of the hippocampus in the context-specific retrieval of extinction has begun to receive attention, no explicit attempts have been made to elucidate a role for the hippocampus in encoding the context specificity of extinction. Permanent hippocampal lesions do not affect extinction per se (Wilson et al., 1995; Frohardt et al., 2000; Ji and Maren, 2005), but at least one report suggests that these lesions affect the context dependency of extinction (Ji and Maren, 2005) (cf. Wilson et al., 1995; Frohardt et al., 2000). However, it is not clear whether this deficit is attributable to a failure to properly encode or retrieve extinction in rats with permanent hippocampal lesions.

In previous studies, reversible inactivation techniques were used to isolate roles for the hippocampus in both encoding and retrieval processes for spatial memory (Riedel et al., 1999). Moreover, we showed that inactivation of the dorsal hippocampus before testing disrupts the context-specific retrieval of fear extinction (Corcoran and Maren, 2001, 2004). In the present experiments, we infused the $\mathrm{GABA}_{\mathrm{A}}$ receptor agonist muscimol into the dorsal hippocampus before extinction training to study its role in encoding the context specificity of extinction (Table 1). Given the involvement of the hippocampus in contextual encoding processes, we hypothesized that hippocampal inactivation 
Table 1. Experimental designs

\begin{tabular}{llllllll}
\hline Experiment & Day 1 & Day 2 & Day 3 & Day 4 & Day 5 & Day 6 & Day 8 \\
\hline Corcoran and Maren, 2001,2004 & Cond & Ext 1 & Ext 2 & Ext 3 & Ext 4 & Ext 5 & Test $^{*}$ \\
Experiment 1 & Cond & Ext 1* & Test & & & & \\
Experiment 2 & Cond & Ext 1 & Test* & & & &
\end{tabular}

In previous studies, rats were given extinction training over $5 \mathrm{~d}$, and intrahippocampal muscimol infusions (asterisks) were given before testing. In the present experiments, intrahippocampal muscimol infusions occurred before extinction training (experiment 1) or before testing (experiment 2) to test a role for the dorsal hippocampus in the contextual encoding of extinction and its context-specific retrieval after a single extinction training session, respectively. Cond, Conditioning; Ext, extinction.

during extinction training would result in a failure of the extinction context to aid the retrieval of extinction during later testing. That is, hippocampal inactivation during extinction training should result in renewal of fear, regardless of the context in which testing occurs.

\section{Materials and Methods}

Experiment 1: hippocampal inactivation disrupts the acquisition and contextual encoding of fear extinction

Although our previous results suggest a role for the dorsal hippocampus in mediating the context specificity of extinction retrieval (Corcoran and Maren 2001, 2004), it is unclear whether the dorsal hippocampus is also involved in the acquisition of fear extinction (Lattal and Abel, 2001; Fischer et al., 2004). Moreover, it has yet to be shown whether the encoding of the context specificity of extinction requires the dorsal hippocampus. In the present experiment, we sought to address these issues by giving extinction training to rats after reversibly inactivating the dorsal hippocampus and by subsequently testing the rats drug-free. We expected that hippocampal inactivation would result in the renewal of fear inside the extinction training context, thereby demonstrating a role for the dorsal hippocampus in the contextual encoding of extinction memory.

Subjects. Subjects were 122 adult male Long-Evans rats (200-224 g) obtained from a commercial supplier (Harlan Sprague Dawley, Indianapolis, IN). After arrival, the rats were housed individually in stainlesssteel hanging cages on a 14/10 h light/dark cycle (lights on at 7:00 A.M.) and were allowed ad libitum access to food and water. After being housed, the rats were handled ( $10-20 \mathrm{~s}$ per rat per day) for $5 \mathrm{~d}$ to habituate them to the experimenter.

Surgery. One week before behavioral testing, rats were implanted with stainless-steel guide cannulas aimed at the dorsal hippocampus. Rats were treated with atropine methyl nitrate $(0.3 \mathrm{mg} / \mathrm{kg}$, i.p.), anesthetized with sodium pentobarbital (Nembutal; $65 \mathrm{mg} / \mathrm{kg}$, i.p.), and mounted in a stereotaxic apparatus (David Kopf Instruments, Tujunga, CA). The scalp was incised and retracted, and the head was positioned to place bregma and lambda in the same horizontal plane. Small holes were drilled through the skull for bilateral placement of stainless-steel guide cannulas (23 gauge; $10 \mathrm{~mm}$ in length; Small Parts, Miami Lakes, FL) into the dorsal hippocampus (3.8 $\mathrm{mm}$ posterior, $2.5 \mathrm{~mm}$ lateral, $2.5 \mathrm{~mm}$ ventral to bregma) along with three jeweler's screws. Cannulas were affixed to the skull, and the scalp incision was closed with dental acrylic. After surgery, stainless-steel obturators (30 gauge; $10 \mathrm{~mm}$ in length; Small Parts) were placed in the guide cannulas. Obturators were replaced every other day throughout the remainder of the experiment.

Behavioral apparatus. Eight identical observation chambers $(30 \times$ $24 \times 21 \mathrm{~cm}$; Med Associates, St. Albans, VT) were used in experiments 1 and 2 . The chambers were constructed from aluminum (side walls) and Plexiglas (rear wall, ceiling, and hinged front door) and were situated in sound-attenuating cabinets located in a brightly lit and isolated room. The floor of each chamber consisted of 19 stainless-steel rods $(4 \mathrm{~mm}$ in diameter) spaced $1.5 \mathrm{~cm}$ apart (center-to-center). Rods were wired to a shock source and solid-state grid scrambler (Med Associates) for the delivery of footshock USs. A speaker mounted outside a grating in one wall of the chamber was used for the delivery of acoustic CSs. Closedcircuit video cameras mounted above each chamber were used to videotape the behavior of each rat. Sensory stimuli were adjusted within these chambers to generate three distinct contexts. For the first context, a $15 \mathrm{~W}$ houselight mounted opposite the speaker was turned on, and room lights remained on. The chambers were cleaned with a $1 \%$ acetic acid solution, and stainless-steel pans containing a thin film of the same solution were placed underneath the grid floors to provide a distinct odor before the rats were placed inside. Ventilation fans in each cabinet supplied background noise (65 dB, A scale). Rats were transported to this context in white plastic boxes. For the second context, all room and chamber houselights were turned off; a pair of $40 \mathrm{~W}$ red lights provided illumination. Additionally, the doors on the sound-attenuating cabinets were closed, the ventilation fans were turned off, and the chambers were cleaned with a $1 \%$ ammonium hydroxide solution. To provide a distinct odor, stainless-steel pans containing a thin film of this solution were placed underneath the grid floors before the rats were placed inside. Rats were transported to this context in black plastic boxes. In the third context, all of the room lights were turned off; the $15 \mathrm{~W}$ houselights provided illumination. The ventilation fans in the sound-attenuating cabinets were turned off, and the chambers were cleaned with a $70 \%$ ethanol solution. To provide a distinct odor, stainless-steel pans containing a thin film of the ethanol solution were placed underneath the grid floors before the rats were placed in the chambers. Additionally, clear rubber mats were placed over the grids to provide a unique texture. Rats were transported to this context in opaque gray plastic garbage cans.

Procedure. Rats were given 1 week after surgery for recovery and then submitted to three experimental phases: fear conditioning, extinction, and testing. For this experiment, "context A" refers to the context in which fear conditioning occurred, whereas "context B" and "context C" refer to other contexts. The actual contexts in which the experimental phases occurred were counterbalanced across groups. For fear conditioning, rats were transported in squads of eight and were placed in the conditioning chambers; chamber position was counterbalanced for each squad. The rats received five tone $(10 \mathrm{~s} ; 80 \mathrm{~dB} ; 2 \mathrm{kHz})$-footshock ( $1 \mathrm{~s} ; 1$ $\mathrm{mA}$ ) trials [70 s intertrial interval (ITI)], beginning 3 min after being placed in context A. Sixty seconds after the final shock, the rats were returned to their home cages.

The extinction phase began $24 \mathrm{~h}$ after the conditioning session and consisted of a single extinction training session and a single exposure session given over $2 \mathrm{~d}$. The extinction training and exposure sessions were each $55.5 \mathrm{~min}$ in duration, and the order of extinction training and exposure were counterbalanced such that approximately one-half of the rats received extinction training on each of the $2 \mathrm{~d}$. During extinction training, rats were presented with 45 tone presentations (10 s; $80 \mathrm{~dB} ; 2$ $\mathrm{kHz}$; $60 \mathrm{~s} \mathrm{ITI)} \mathrm{without} \mathrm{the} \mathrm{footshock} \mathrm{US,} \mathrm{beginning} 3$ min after placement in the context. The purpose of the exposure session was to equate context exposure across groups so that testing never occurred in a novel context. During the exposure session, rats were placed in a context different from the extinction context but were not presented with any CSs.

Extinction training occurred in either the original conditioning context (A) or in a second context (B). After the extinction phase, testing occurred in context $\mathrm{A}, \mathrm{B}$, or $\mathrm{C}$, such that all rats were in either the $\mathrm{ABA}$, $\mathrm{AAB}, \mathrm{ABB}$, or $\mathrm{ABC}$ testing group. Testing groups were collapsed so that rats tested in the context consistent $(\mathrm{CON})$ with extinction training (ABB) formed one group, whereas rats tested in a context inconsistent (INCON) with extinction training (ABA, AAB, or $\mathrm{ABC}$ ) formed another group (see Results). Testing occurred $24 \mathrm{~h}$ after the last day of the extinction phase. Rats were brought back to the conditioning chambers and presented with 10 tones $(10 \mathrm{~s} ; 80 \mathrm{~dB} ; 2 \mathrm{kHz} ; 60 \mathrm{~s} \mathrm{ITI})$, beginning $3 \mathrm{~min}$ after placement in the test context.

Intracranial drug infusions. Twenty to $25 \mathrm{~min}$ before extinction training, rats were transported to an infusion room in squads of four in opaque white plastic buckets with pine shavings covering their floors. On arrival in the infusion room, the obturators were removed from the rats' guide cannulas. Stainless-steel injection cannulas (30 gauge; $11 \mathrm{~mm}$ in length; Small Parts), which were connected by polyethylene tubing (PE20; Small Parts) to $10 \mu \mathrm{l}$ syringes mounted in an infusion pump (Harvard Apparatus, South Natick, MA), were placed in the guide cannulas. Rats received an infusion of sterile physiological saline (0.9\%; SAL group) or 
muscimol (MUS group) ( $1 \mu \mathrm{g} / \mu \mathrm{l}$ dissolved in $0.9 \%$ sterile saline; Sigma, St. Louis, MO) at a rate of $0.32 \mu \mathrm{l} / \mathrm{min}$ for $94 \mathrm{~s}$, resulting in a $0.5 \mu \mathrm{l}$ infusion (i.e., $0.5 \mu \mathrm{g}$ muscimol per hemisphere). Under these conditions, muscimol inactivates brain tissue within $2 \mathrm{~mm}$ of the infusion site based on measurements of $\left[{ }^{3} \mathrm{H}\right]$ muscimol binding and 2-deoxyglucose activity (Martin, 1991). In experiment 3, we confirm this and demonstrate that our infusion procedure produces muscimol spread within, but not beyond, a substantial portion of the dorsal hippocampus. After the infusion pumps were shut off, rats remained in the buckets with the injection cannulas in place for $1 \mathrm{~min}$ to allow for diffusion of the drug. The injection cannulas were removed, obturators were replaced in the guide cannulas, and the rats were returned to their home cages until extinction training began. The infusion squads were counterbalanced for both extinction training context and infusion, yielding a total of four groups: CON/MUS $(n=21)$, INCON/MUS $(n=38)$, CON/SAL $(n=23)$, and INCON/SAL $(n=39)$. No infusions were given before the exposure session.

Fear to the tone CS was assessed by measuring freezing behavior, as described previously (Maren, 1998). Because of technical difficulties, however, a subset of the rats did not have their extinction sessions digitally recorded. For these rats, the output from video cameras mounted above each chamber was fed into a video processor (Robot, San Diego, $\mathrm{CA}$ ). Freezing behavior was scored off-line from videotape, using a timesampling procedure, by an experimenter who was blind to both the infusions that the rats had received and the nature (CON vs INCON) of the testing context for the rats. Measurements were made every $6 \mathrm{~s}$ for each rat, yielding 10 observations per post-CS minute during the extinction sessions. Freezing was quantified by computing the percentage of observations in which the rats had been scored as freezing for each post-CS minute.

Histology. Histological verification of cannula placements was performed after behavioral testing. Rats were perfused across the heart with physiological saline, followed by a $10 \%$ formalin solution. After extraction from the skull, brains were postfixed in $10 \%$ formalin solution for $2 \mathrm{~d}$, at which time the solution was replaced with a $10 \%$ formalin $/ 30 \%$ sucrose solution until sectioning. Sections ( $40 \mu \mathrm{m}$ thick) were cut on a cryostat $\left(-19^{\circ} \mathrm{C}\right)$, wet mounted on microscope slides, and stained with $0.25 \%$ thionin for visualization of cannula and injector tracts.

Data analysis. For each session, the freezing data were transformed to a percentage of the total observations, a probability estimate that is amenable to analysis with parametric statistics. These probability estimates of freezing were analyzed using ANOVA. Post hoc comparisons in the form of Fisher's PLSD tests were performed after a significant omnibus $F$ ratio. All data are represented as means \pm SEMs.

Experiment 2: hippocampal inactivation disrupts the contextspecific retrieval of extinction after a single extinction session In previous experiments, we observed that inactivation or lesions of the dorsal hippocampus before testing resulted in equal, low levels of freezing regardless of the context in which testing occurred (Corcoran and Maren, 2001, 2004; Ji and Maren, 2005). We interpreted this effect to suggest that hippocampal inactivation disrupts the context-specific retrieval of extinction. In experiment 1 , we found that rats that had received inactivation of the dorsal hippocampus before extinction training demonstrated renewal during testing regardless of the testing context. This effect suggests that the dorsal hippocampus encodes the context specificity of extinction. Dorsal hippocampal inactivation during extinction training blocked the linkage of the extinction memory to the context in which it was learned. Failure of the context to retrieve the extinction memory during testing led to renewal of fear, even in the extinction training context. In experiment 1 , however, rats received only a single extinction training session, as opposed to the multiple extinction training sessions distributed over multiple days in our previous work. The present experiment was conducted to verify that the context-specific retrieval of extinction acquired during a single extinction training session also requires the dorsal hippocampus.

To this end, rats were given fear conditioning and extinction training as in experiment 1 , except that intrahippocampal infusions were given before testing rather than before extinction training.
Subjects. Subjects were 32 adult male Long-Evans rats (200-224 g) obtained and housed as described in experiment 1.

Surgery and behavioral apparatus. Surgical procedures and behavioral apparatus were as described in experiment 1, except that only two contexts, $\mathrm{A}$ and $\mathrm{B}$, were used throughout conditioning, extinction, and testing phases.

Procedure and intracranial drug infusions. Rats were fear conditioned in context $\mathrm{A}$ as described in experiment 1 . After conditioning, rats were given extinction training and exposure sessions in contexts $\mathrm{A}$ and $\mathrm{B}$ as described in experiment 1 . In this experiment, all rats received exposure on the first day and extinction training on the second day of the extinction phase. Twenty-four hours after the extinction training session, rats were given infusions of MUS or SAL, as described in experiment 1. Twenty to $25 \mathrm{~min}$ after the infusion procedure, rats were tested in either the context consistent with extinction training (ABB; $\mathrm{CON}$ group) or the context inconsistent with extinction training (AAB; INCON group). After one unsuccessful infusion, this procedure yielded four groups: $\mathrm{CON} /$ SAL $(n=8)$, CON/MUS $(n=8)$, INCON/SAL $(n=7)$, and INCON/ $\operatorname{MUS}(n=8)$.

Histology and data analysis. Histological procedures were as described in experiment 1 . Freezing behavior was analyzed as described in experiment 1 .

\section{Experiment 3: autoradiographic analysis of muscimol diffusion in} the dorsal hippocampus

We estimated that muscimol infusions in our previous experiments (Holt and Maren, 1999; Corcoran and Maren, 2001, 2004) inactivated a significant portion of the dorsal hippocampus without severely affecting adjacent structures, based on measurements of the spread of $\left[{ }^{3} \mathrm{H}\right]$ muscimol in the sensorimotor cortex (Martin, 1991; Martin and Ghez, 1999). Although the extent of muscimol diffusion has been measured in several cortical (Martin, 1991) and subcortical (Edeline et al., 2002) regions, there has been no such measurement of the spread of muscimol in the dorsal hippocampus. We therefore used quantitative autoradiography to measure the diffusion of $\left[{ }^{3} \mathrm{H}\right]$ muscimol after infusion into the dorsal hippocampus.

Subjects. The subjects were 20 adult male Long-Evans rats (200-224 g) obtained and housed as described in experiment 1.

Surgery. Surgical procedures were as described in experiment 1

Procedure, intracranial drug infusions, and histology. Rats were given at least $7 \mathrm{~d}$ to recover from surgery. All rats underwent behavioral testing as part of other experiments that ended at least $2 \mathrm{~d}$ before the present experiment was performed. On arrival in the infusion room, obturators were removed from the guide cannulas, and rats were given infusions of SAL into one hemisphere and $\left[{ }^{3} \mathrm{H}\right]$ muscimol (PerkinElmer, Boston, MA) [specific activity, $30.00 \mathrm{Ci} / \mathrm{mmol}$, added to $1 \mu \mathrm{g} / \mu \mathrm{l}$ muscimol (Sigma) dissolved in $0.9 \%$ sterile saline] into the other hemisphere, as described in experiment 1 . The hemisphere into which muscimol was infused was counterbalanced across all rats. After the infusion procedure, rats were returned to their home cages until being killed.

All rats were killed at one of four time intervals after the end of the infusion, yielding four groups in this experiment: $0 \mathrm{~min}$ (immediate; $n=$ 7), $20 \mathrm{~min}(n=3), 60 \mathrm{~min}(n=6)$, or $360 \mathrm{~min}(n=4)$. After the appropriate time interval, rats were killed via carbon dioxide asphyxiation and were decapitated. Brains were removed and frozen in crushed dry ice, coated with frozen tissue-embedding medium (Lipshaw, Detroit, MI) to prevent desiccation, and maintained at $-80^{\circ} \mathrm{C}$ until sectioning. Pairs of adjacent brain sections (20 $\mu \mathrm{m}$ thick) were cut on a cryostat $\left(-15\right.$ to $\left.-22^{\circ} \mathrm{C}\right)$ at $200 \mu \mathrm{m}$ intervals, thaw mounted onto polylysinesubbed microscope slides, and allowed to air dry. Groups of $\sim 20$ slides were made from tissue representing the entire rostrocaudal extent of the hippocampus.

Data analysis. Tissue samples were visualized using a Fuji BAS-1800 phosphorimager (Fuji Medical Systems, Stamford, CT). Calibrated plastic radioactive standards were included with each cassette of slides to allow for variation in exposure, as described previously (Pan et al., 1983). After development, regions of interest including visually apparent radioactivity were hand drawn and measured for radioactive density and area. Autoradiograms were analyzed by computer-assisted video densitome- 


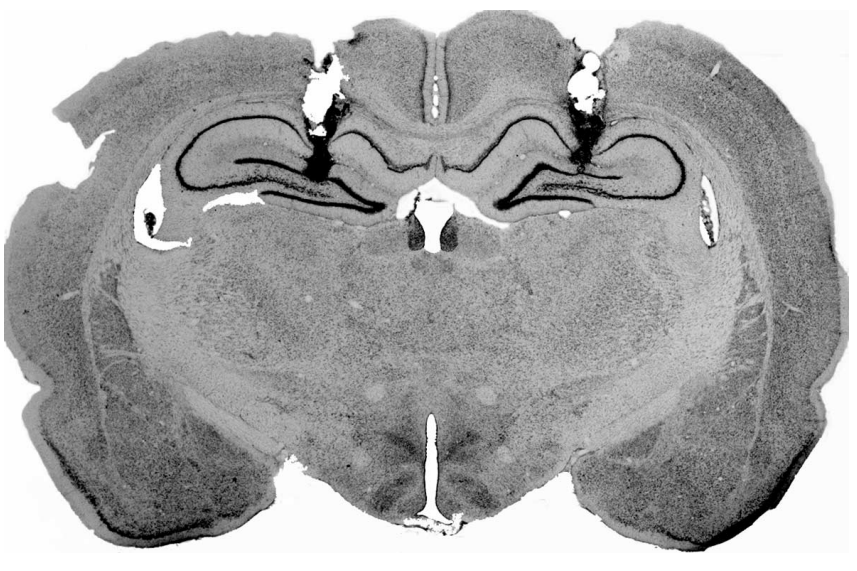

Figure 1. Cannula placement in the dorsal hippocampus (experiment 1). Photomicrograph showing a thionin-stained coronal section from the brain of a rat with representative cannula placements in the dorsal hippocampus.

try (MCID; Imaging Research, St. Catharines, Ontario, Canada). Imaging plate densities were converted to apparent tissue radioactivity based on the radioactive standards and the specific activity of the $\left[{ }^{3} \mathrm{H}\right]$ muscimol used. Radioactive densities were calculated as femtomoles per microgram of protein and were averaged across adjacent sections. Comparisons between the four groups were made using ANOVA. Post hoc comparisons in the form of Fisher's PLSD tests were performed after a significant omnibus $F$ ratio. All data are represented as means \pm SEMs. Identification of brain regions was made via comparison of the autoradiograms to a stereotaxic atlas (Swanson, 1992).

\section{Results \\ Experiment 1 \\ Histology}

The photomicrograph in Figure 1 illustrates a representative cannula placement in the dorsal hippocampus. Figure 2 represents the guide cannula tip placements for all rats included in the analysis. Cannula placements were symmetrical throughout the rostrocaudal extent of the dorsal hippocampus and did not consistently differ across groups. Placement of the guide cannulas into the dorsal hippocampus damaged some cortical tissue and caused compression of hippocampal tissue. This damage was limited to the area immediately surrounding the cannulas. The pattern of results from saline controls in this experiment (see below) did not differ from that of unoperated animals in a previous experiment (Corcoran and Maren, 2001), suggesting that mere placement of the guide cannulas in the dorsal hippocampus had no significant effect on behavior.

\section{Behavior}

Infusion groups were matched for freezing averaged across the last 2 postshock minutes of the conditioning session $\left(F_{(1,119)}=\right.$ 0.21 ; data not shown). One rat was removed from the final analysis for failing to acquire conditional freezing during the conditioning session $(<15 \%$ freezing averaged across the last 2 postshock minutes). Freezing data during extinction training were collapsed across the extinction contexts and are shown in Figure $3 A$. Before the onset of the first CS-alone presentation, there was no effect of MUS infusions on levels of freezing $\left(F_{(1,119)}=0.009\right)$. Freezing declined significantly across the 45 post-CS minutes of the extinction training session $\left(F_{(47,5593)}=33.30 ; p<0.0001\right)$. There was a significant main effect of infusion $\left(F_{(1,119)}=5.12\right.$; $p=0.03)$; post hoc tests $(p<0.05)$ confirmed that rats in the MUS group froze more across the extinction training session than SAL rats (mean percentages freezing for the last 5 post-CS

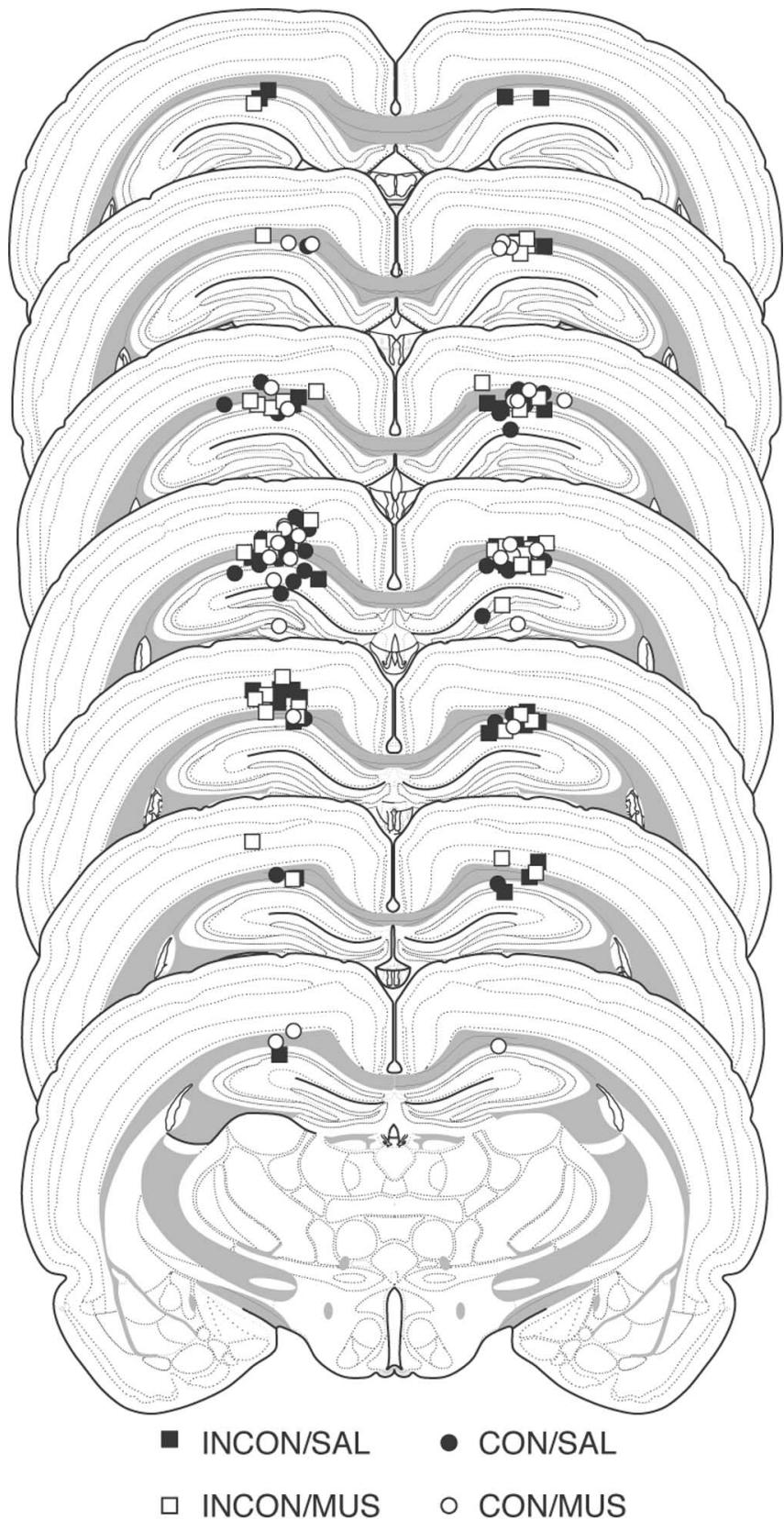

Figure 2. Illustration of guide cannula placements in the dorsal hippocampus (experiment 1). Placements represented are from most rats included in the final analysis; many rats were transported to another laboratory for use in another experiment (INCON/SAL, filled squares; INCON/MUS, open squares; CON/SAL, filled circles; CON/MUS, open circles). Atlas templates were adapted from Swanson (1992).

minutes were $40.74 \pm 3.99$ and $23.97 \pm 3.19$, respectively). In addition, ANOVA revealed a significant interaction of infusion by post-CS minute $\left(F_{(47,5593)}=3.51 ; p<0.0001\right)$. Given that muscimol had no effect on pretone freezing levels, these data suggest that hippocampal inactivation blunted the acquisition of extinction.

Testing occurred either inside the rats' extinction training context (CON group) or in another context (INCON group). Freezing during the pre-CS period was similar across infusion groups $\left(F_{(1,119)}=0.91\right.$; data not shown). Figure $3 B$ shows conditional freezing averaged across the first 6 post-CS minutes of the testing session for each group; these averages were normalized by 
subtracting pre-CS baseline freezing levels for each rat. We used only the first 6 min of the test session because fear rapidly extinguished during the test session, thereby occluding any group differences. One-way ANOVA revealed a significant effect of group on freezing during the test session $\left(F_{(3,117)}=4.0 ; p=0.01\right)$. Post hoc tests $(p<0.05)$ indicated that rats in the CON/ SAL group froze less during testing than all other groups and that there were no differences between the other groups.

Collectively, these data demonstrate that, among rats that had received saline infusions before extinction training, significant renewal was later seen when testing occurred outside the extinction context. Among rats that had received muscimol before extinction training, no renewal was seen among rats tested outside their extinction context relative to those tested in their extinction context, although all muscimol-treated rats froze more than rats in the CON/SAL condition. Proper interpretation of this result is made difficult, however, by the preexisting differences between muscimol- and salinetreated rats at the end of the extinction training session. Freezing levels among MUS rats during testing were equal to their high freezing levels at the end of extinction training; interpretation of this effect is therefore confounded by a potential ceiling effect on renewed freezing.

To more directly assess the effects of pre-extinction training hippocampal inactivation on behavior during testing, we reanalyzed extinction training and testing data using only a subset of the rats that had received muscimol before extinction training. By excluding MUS rats freezing $>65 \%$ averaged across the last 5 post-CS minutes of extinction training (final $n=16$ and 27 for CON/MUS and INCON/MUS, respectively), we were able to equate extinction between MUS and SAL groups (mean percentages freezing for the last 5 post-CS minutes were $24.39 \pm 2.42$ and $23.97 \pm 3.19$, respectively; all SAL rats remained in this analysis) (Fig. 3C). During testing, a similar pattern of freezing was seen among these rats, as seen previously (Fig. 3D); one-way ANOVA again revealed a significant effect of group $\left(F_{(3,101)}=2.8 ; p=\right.$ $0.04)$. Again, post hoc tests indicated that INCON/SAL rats demonstrated renewal by freezing more than CON/SAL rats. INCON/ MUS rats froze more than CON/SAL rats, and there was a strong trend for CON/MUS rats to freeze more than CON/SAL rats $(p<0.07)$. These results suggest that pre-extinction training inactivation of the dorsal hippocampus does not disrupt later renewal of freezing outside the extinction context. However, muscimol did disrupt the expression of extinction in the context in which extinction training was conducted, leading to an inappropriate renewal of fear in the CON/MUS rats. As a result, the effect of pre-extinction training MUS on renewal cannot be explained by differences in freezing levels at the end of extinction training. Rather, the high levels of freezing seen during testing among all rats that received pre-extinction training muscimol infusions reflect renewal of fear, regardless of the context in which testing occurred.
B

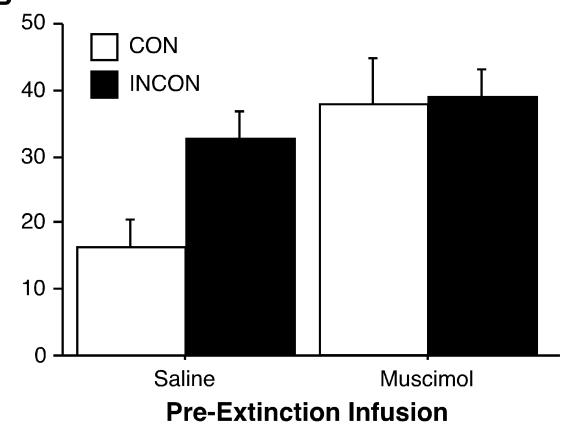

D

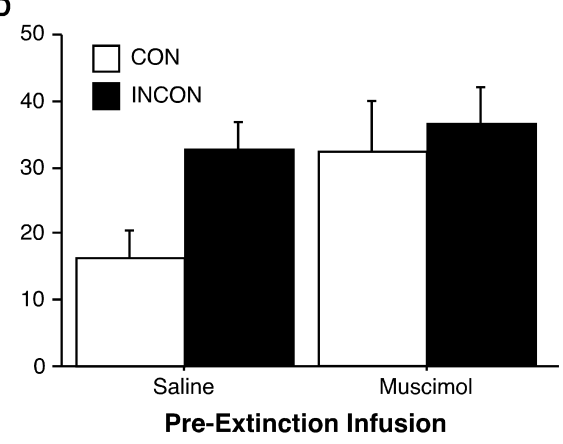




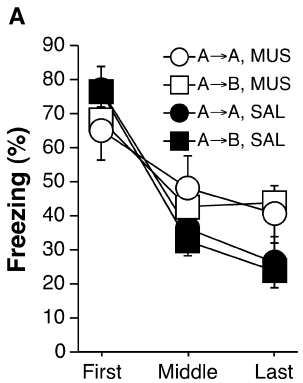

Extinction Block

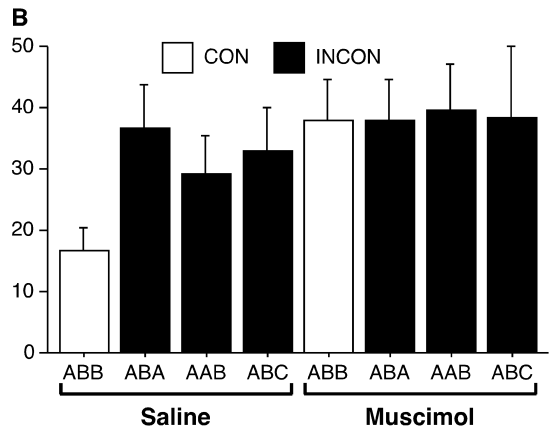

Figure 4. Effects of hippocampal inactivation on extinction training and testing did not differ across contexts. $\boldsymbol{A}$, Freezing behavior averaged across the first 3 , middle 3 , and final 3 post-CS minutes of the extinction training session. All rats were fear conditioned in context $A$. Extinction training occurred the next day, in either the same context as conditioning $(A \rightarrow A$; circles) or a new context (context $B ; A \rightarrow B$; squares) after infusions of either muscimol (open symbols) or saline (filled symbols). $\boldsymbol{B}$, Renewal of fear to the CS was similar among all INCON/ SAL, CON/MUS, and INCON/MUS groups, relative to the CON/SAL group (CON groups, open bars; INCON groups, filled bars). Muscimol and saline refer to infusions given before extinction training. All data are presented as means \pm SEM.

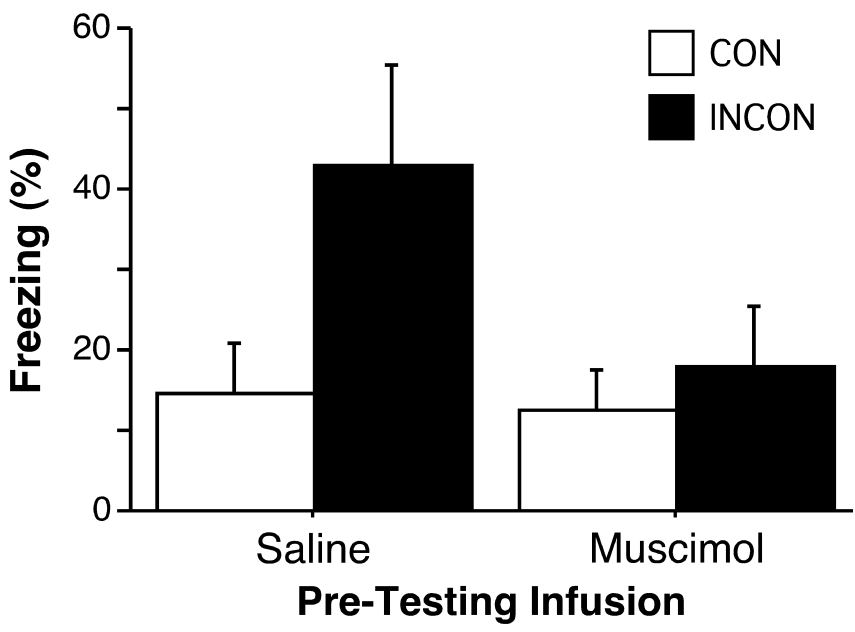

Figure 5. Hippocampal inactivation before testing disrupts renewal of fear after a single extinction training session (experiment 2). Mean \pm SEM percentage of freezing averaged across the first 5 post-CS minutes during testing. Rats were tested either in a context consistent with extinction training (open bars) or in a context inconsistent with (S-alone presentations during the extinction training (filled bars). Testing took place 20-25 min after an intrahippocampal infusion of either saline or muscimol.

During testing, muscimol infusions into the dorsal hippocampus did not affect baseline freezing levels before CS onset $\left(F_{(1,29)}=0.001\right.$; data not shown $)$. However, hippocampal inactivation did influence conditional freezing to the tone CS during testing, as shown in Figure 5. As in experiment 1, we excluded the last 5 post-CS minutes from the analysis, because renewed fear was rapidly extinguished among INCON/SAL rats. In addition, these data were normalized by subtracting the rats' pre-CS baseline freezing levels. One-way ANOVA revealed a significant effect of testing group on freezing averaged across the first 5 post-CS minutes of the test $\left(F_{(3,27)}=2.99 ; p=0.05\right)$. Post hoc comparisons $(p<0.05)$ revealed that rats in the INCON/SAL group froze more than any other group and that there were no significant differences among the other three groups. These results extend our previous findings of a role for the dorsal hippocampus in the context-specific expression of extinction (Corcoran and Maren, 2001, 2004; Ji and Maren, 2005) and demonstrate the necessity of hippocampal involvement in the context-specific expression of extinction after only one extinction training session.

\section{Experiment 3}

Autoradiographic $\left[{ }^{3} \mathrm{H}\right]$ muscimol images overlaid on cresylviolet-stained sections from representative rats from each infusion-kill interval are shown in Figure 6. Although $\sim 20$ sections were taken through each rat's hippocampus, only seven from each rat are shown in Figure 6. Visual inspection of the sections revealed that rats killed at 0,20 , and $60 \mathrm{~min}$ after infusion retained strong radioactive signal across many sections, whereas there was very little signal remaining 360 min after infusion. Some muscimol infused into the hippocampus diffused up the length of the guide cannula, resulting in the spread of the drug to some areas of parietal association cortex overlying the hippocampus. Muscimol did not spread into ventral hippocampus or thalamus.

For each rat, the section in which radioactive density was highest was assumed to be closest to the site of infusion. Figure 7 depicts the average radioactive density of all sections relative to the section with the maximum density. ANOVA revealed main effects of time interval between infusion and killing $\left(F_{(3,16)}=8.84 ; p=0.001\right)$ and of distance from the center section $\left(F_{(18,288)}=8.11 ; p<0.0001\right)$ on the amount of signal present. In addition, there was a significant interaction of time interval by distance from the center section $\left(F_{(54,288)}=3.9 ; p<0.0001\right)$, suggesting that the spread of muscimol from center was not equivalent for all groups. Post hoc tests $(p<0.05)$ revealed that, although densities in the immediate group were higher than those in any other group, there were no differences between the 20,60 , and 360 min groups. This surprising result was most likely attributable to reduced statistical power based on the low number of subjects in the $360 \mathrm{~min}$ group. However, if densities from all sections are recalculated as percentages of the density in the center section (data not shown), a different pattern of results emerges. ANOVA performed on these recalculated data revealed the same main effects of time interval $\left(F_{(3,16)}=7.73 ; p=0.002\right)$ and distance from center $\left(F_{(18,54)}=42.7 ; p<0.0001\right)$ and the same interaction effect of time interval by distance from center $\left(F_{(54,288)}=3.35 ; p<0.0001\right)$. However, post hoc comparisons in this case revealed that, although the immediate, 20, and $60 \mathrm{~min}$ groups were similar to one another, each of these groups maintained a greater percentage of maximum radioactive density over the series of sections taken than the 360 min group. In fact, sections from only one of the four rats in the 360 min group had any measurable radioactive signal at all.

Areas of radioactive signal were irregularly shaped, making it difficult to calculate the volume of tissue to which muscimol was bound. We were, however, able to calculate the linear spread across the rostrocaudal extent of the hippocampus, as well as the two-dimensional area of spread at the center of the infusion. These data are shown in Figure 8, $A$ and $B$, respectively. One-way ANOVA revealed a significant effect of infusion-to-kill interval on the linear spread of muscimol $\left(F_{(3,16)}=11.17 ; p=0.0003\right)$. Post hoc comparisons confirmed that, although the spread of muscimol was similar for rats in the immediate, 20, and 60 min groups (average total spread, $1.84 \mathrm{~mm}$ ), all three of these groups demonstrated greater spread than the $360 \mathrm{~min}$ group (average total spread, $0.15 \mathrm{~mm}$ ). The minimum distance for muscimol spread among the immediate, 20, and 60 min groups was $0.8 \mathrm{~mm}$, and the maximum was $1.8 \mathrm{~mm}$ from the center of the infusion. Additionally, there was a significant effect of time interval on the area of tissue to which muscimol was bound at the center of the 
infusion $\left(F_{(3,16)}=7.12 ; p=0.003\right)$. Although the differences between the immediate, 20, and 60 min groups were again nonsignificant, these groups had a significantly larger area of diffusion at the center of the infusion (average area of spread, $8.08 \mathrm{~mm}^{2}$ ) than the $360 \mathrm{~min}$ group (average area of spread, $0.81 \mathrm{~mm}^{2}$ ). Together, these data suggest that muscimol rapidly spreads to its maximal extent after infusion and remains bound there for at least $1 \mathrm{~h}$. However, within $\sim 6 \mathrm{~h}$ of the infusion, muscimol is cleared from the tissue.

\section{Discussion}

In the present experiments, inactivation of the dorsal hippocampus before extinction training attenuated, but did not entirely block, the acquisition of extinction; rats that had received intrahippocampal infusions of muscimol before extinction training decreased their freezing response across the extinction training session, although not to the same degree as controls. Moreover, hippocampal inactivation during extinction training disrupted the contextual encoding of extinction memory, because rats that had received intrahippocampal infusions of muscimol before extinction training showed renewal of fear even when tested inside their extinction-training context. In two previous studies, pretesting hippocampal inactivation disrupted the context-specific retrieval of extinction memories acquired over multiple extinction training sessions (Corcoran and Maren, 2001, 2004). We replicated this effect in experiment 2 with rats that had been given a single extinction training session, suggesting that the number of extinction training sessions given does not affect the hippocampal contribution to fear extinction. Last, autoradiographic analysis of the spread of $\left[{ }^{3} \mathrm{H}\right]$ muscimol suggested that, although muscimol infused into the hippocampus may diffuse to more dorsal cortical regions, it does not bind to other subcortical structures. Collectively, our present and previous (Corcoran and Maren, 2001, 2004) results support the hypothesis that the hippocampus is necessary for the contextual encoding and context-specific retrieval of extinction memory.

The argument for a hippocampal role in the contextual control of extinction rests on the assumption that our intrahippocampal muscimol infusions have, in fact, selectively affected the dorsal hippocampus. In agreement with this, autoradiographic mapping indicates that the spatial and temporal pattern of muscimol diffusion is confined to the dorsal hippocampus and overlying cortex near the infusion site. Therefore, the effects of dorsal hippocampal inactivation that we observed on the contextual encoding and retrieval of extinction memory, as well as the effects observed by others after dorsal hippocampus muscimol infusions (Mao and Robinson, 1998; Holt and Maren, 1999; Matus-Amat et al., 2004) are specifically attributable to the disruption of hippocampal neuronal activity and not to the inadvertent inactivation of other structures. For example, it is important that muscimol did not spread to the auditory thalamus $(\approx 3.7$ $\mathrm{mm}$ from our infusion site), because lesions of this area disrupt conditioning to auditory CSs (LeDoux et al., 1986). Although we did observe spread of muscimol into areas of parietal association cortex dorsal to the hippocampus, this structure is not involved in normal hippocampal function or in fear/extinction processes.

\section{Distance from Center of Infusion ( $\mathrm{mm}$ )}

Caudal

0.4
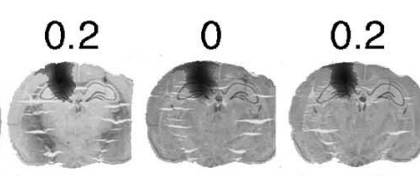

0.4

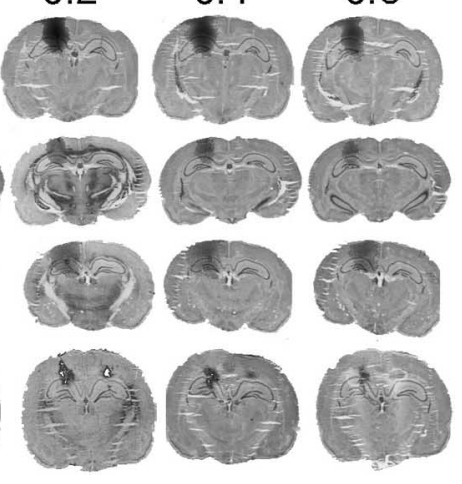

0.6
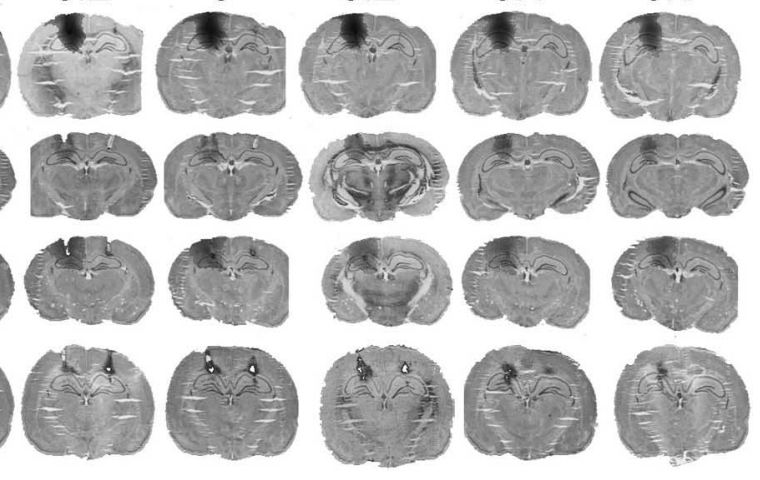

of $\left[{ }^{3} \mathrm{H}\right]$ muscimol were made and overlaid on postfixed cresyl-violet-stained sections. Rats were killed immediately $(0 \mathrm{~min}), 20,60$, or 360 min after intrahippocampal $\left[{ }^{3} \mathrm{H}\right]$ muscimol infusions. Sections shown are from representative rats from each infusionkilling interval and range from $0.6 \mathrm{~mm}$ rostral (leftmost section) to $0.6 \mathrm{~mm}$ caudal (rightmost section) to the infusion site.

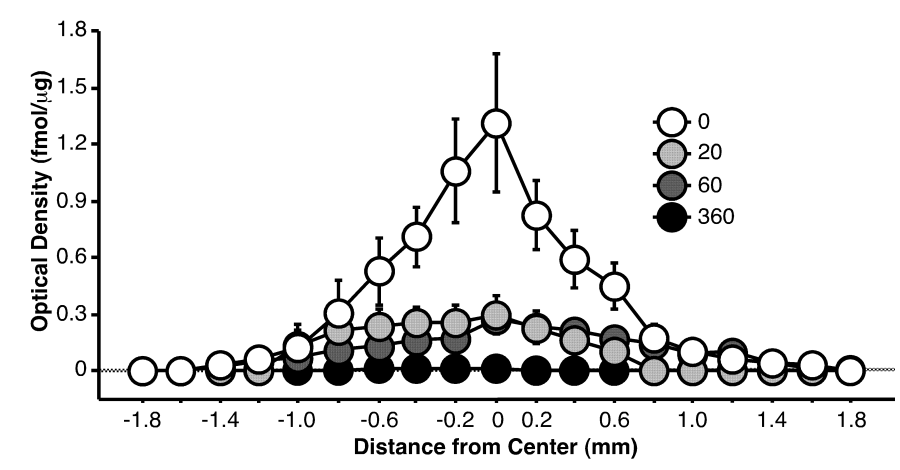

Figure 7. Diffusion of $\left[{ }^{3} \mathrm{H}\right]$ muscimol away from the site of infusion (experiment 3 ). Mean \pm SEM apparent density from tissue sections taken throughout the rostrocaudal extent of the hippocampus. Sections from each rat having the maximum density throughout the infused area were placed at distance zero; all other sections were placed according to their relative distances from those sections. Rats were killed at one of four time intervals after [ $\left.{ }^{3} \mathrm{H}\right]$ muscimol infusion: immediately (0 min; white circles), $20 \mathrm{~min}$ (light gray circles), $60 \mathrm{~min}$ (dark gray circles), or 360 $\min$ (black circles).

Moreover, one recent study demonstrated that electrolytic lesions of the dorsal hippocampus, which spare this overlying cortical tissue, also mitigate the renewal of fear outside of extinction contexts (Ji and Maren, 2005). It is therefore unlikely that the behavioral effects observed after dorsal hippocampal muscimol infusions are attributable to diffusion of the drug into dorsal cortical regions.

Recent research has begun to elucidate the neural mechanisms that mediate the acquisition, consolidation and retrieval, and context specificity of memories for fear extinction (Maren and Quirk, 2004). A network of brain structures including the amygdala (Davis, 2002; Davis et al., 2003), prefrontal cortex (Milad and Quirk, 2002; Santini et al., 2004), and hippocampus (Corcoran and Maren, 2001, 2004) has been identified in mediating these processes, respectively, although functional overlap among these structures does exist. For instance, rearrangement of cytoarchitectural elements in the hippocampus has been demonstrated to serve the acquisition of extinction (Fischer et al., 2004). The results of the present study suggest that the hippocampus is not essential for the acquisition of extinction per se, because rats 
A

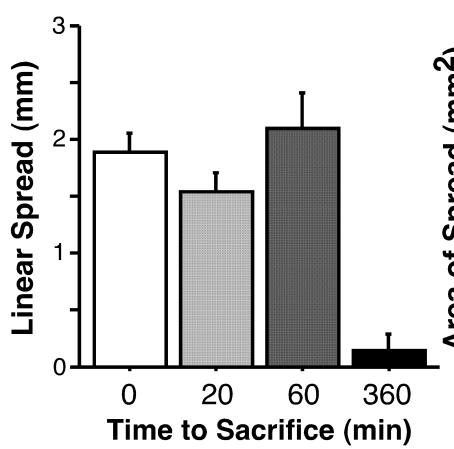

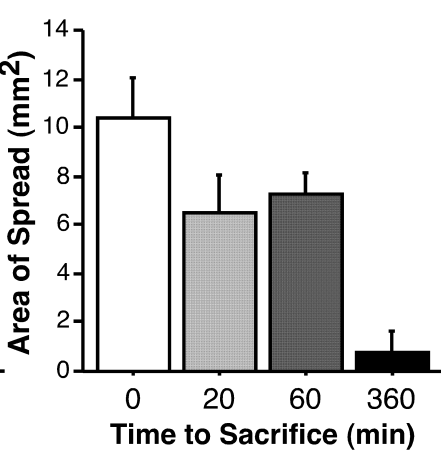

Figure 8. Spread of $\left[{ }^{3} \mathrm{H}\right]$ muscimol in the hippocampus (experiment 3). $\boldsymbol{A}$, Extent of rostrocaudal spread of $\left[{ }^{3} \mathrm{H}\right]$ muscimol through the hippocampus. Mean \pm SEM distance from the first to the last of the tissue sections taken in which radioactive signal was apparent. $\boldsymbol{B}$, Mean \pm SEM two-dimensional area of $\left[{ }^{3} \mathrm{H}\right]$ muscimol spread in the tissue section having the maximum apparent radioactive density. This section was assumed to be at or near the center of the infusion. Rats were killed at one of four time intervals after [ $\left.{ }^{3} \mathrm{H}\right]$ muscimol infusion: immediately $(0 \mathrm{~min}$; white bars), $20 \mathrm{~min}$ (light gray bars), $60 \mathrm{~min}$ (dark gray bars), or $360 \mathrm{~min}$ (black bars).

infused with muscimol were able to significantly reduce conditional responding to the tone over the course of the extinction training session, although the attenuation in extinction relative to control rats does point to an ancillary role for the hippocampus in extinction acquisition. This effect corroborates previous demonstrations of deficits in inhibitory learning after hippocampal lesions (Benoit et al., 1999; Holland et al., 1999).

Alternatively, the hippocampus may be involved in contextual learning during extinction training that itself regulates ongoing extinction performance. Renewal of conditional responding outside of extinction contexts typically diminishes quickly with repeated CS presentations during testing (Bouton and Bolles, 1979; Bouton and Ricker, 1994; Corcoran and Maren, 2001, 2004; Hobin et al., 2003). In fact, this rapid return of extinction is common after other postextinction relapse effects, such as spontaneous recovery (Brooks and Bouton, 1993) and reinstatement (Bouton and King, 1983). Bouton (1994) interpreted these findings to indicate that extinction trials become part of the extinction training context itself, such that early test trials, which essentially are extinction trials, act as reminder cues that have the ability to retrieve the memory for extinction (Brooks and Bouton, 1993, 1994). Each CS-alone presentation during extinction training could conceivably retrieve memory for all previous CS-alone presentations. Stated simply, presentation of the CS without the US is itself part of the extinction context and will tend to remind the rat that the CS is safe. Insofar as the hippocampus is involved in cognitive representations of contexts (Fanselow, 2000; Maren et al., 1997; Rudy and O'Reilly, 1999, 2001), hippocampal inactivation during extinction training may have disrupted the inclusion of previous CS-alone trials as part of the extinction training context, thereby decreasing the rate at which freezing to the CS was extinguished.

It is possible, however, that increased freezing during extinction training among muscimol-treated rats was the result of nonassociative augmentation of the freezing CR by hippocampal inactivation. For example, muscimol infusion into the hippocampus might reduce locomotor activity and indirectly enhance freezing behavior. In contrast to this view, we demonstrated previously that hippocampal inactivation does not affect the freezing response to a nonextinguished CS (Corcoran and Maren, 2001) or freezing to a shock-associated context (Holt and
Maren, 1999). Moreover, hippocampal lesions typically cause locomotor hyperactivity (Douglas, 1967) and may decrease freezing behavior under some conditions (Maren and Fanselow, 1997). If hippocampal inactivation were to simply alter the performance of the fear CR, we would expect decreased freezing, if anything, after muscimol infusions. Our inactivation results suggest that hippocampal inactivation specifically affects the processing of contextual and associative cues present at the time of extinction training and retrieval.

In addition to elevating freezing behavior during extinction training, muscimol infusions into the dorsal hippocampus affected the context-specific expression of extinction during drugfree retrieval testing. Specifically, rats treated with muscimol before extinction training exhibited renewal of fear, regardless of the context in which retrieval testing occurred. This renewal of fear was not likely caused by a shift in drug state (i.e., a context shift) from extinction to testing, because intrahippocampal muscimol infusions do not yield generalization decrements in tests of context discrimination (Holt and Maren, 1999). Alternatively, muscimol may have disrupted learning about the context-CS relationship that engenders context-specific conditional responding after extinction training. After extinction training, a CS acquires multiple meanings, both an excitatory CS-US association and an inhibitory CS-"no US" association. Although it is unlikely that extinction-training contexts themselves directly inhibit responding to extinguished CSs (Bouton and Swartzentruber, 1986), they can "set the occasion" for which of these stimulus meanings is retrieved. Bouton (1993) suggested that extinctiontraining contexts act as "negative occasion setters" by signaling that the CS will not be followed by the US. Interestingly, Holland et al. (1999) reported a selective role for the hippocampus in negative occasion setting. A deficit in such an occasion-setting process would predict reduced extinction acquisition as well as an inability to retrieve extinction memories in the contexts in which they were learned. Hence, the present results are consistent with a role for the hippocampus in mediating negative occasion-setting processes during extinction training.

Interestingly, muscimol infusions before testing (experiment 2) (Corcoran and Maren, 2001, 2004) also reduced the context dependency of extinction, but they did so by yielding low levels of freezing in the test contexts (compared with the high levels of freezing observed during testing among muscimol-treated rats in experiment 1). A selective disruption of negative occasion setting does not account for the effects of intrahippocampal muscimol on the expression of extinction (experiment 2) (Corcoran and Maren, 2001, 2004), insofar as that would be expected to increase freezing levels in the extinction context. Rather, we argue that hippocampal inactivation during testing prevents contextual cues from regulating conditional responding altogether. This yields low levels of conditional responding in all test contexts because the extinction memory outcompetes the fear memory for expression in behavior (Maren and Holt, 2000).

Together with previous data (Corcoran and Maren, 2001, 2004), the current experiments elaborate an important role for the dorsal hippocampus in mediating the contextual control of extinction. Emerging evidence suggests that contextual control of memory involves interactions of the hippocampus within a distributed network of interconnected brain structures (Gabriel, 1993). Indeed, the context dependence of extinguished fear memories appears to arise from interactions between the hippocampus, amygdala, and prefrontal cortex (Maren and Quirk, 2004). Recent studies have revealed that CS-evoked single-unit activity in the lateral nucleus of the amygdala, which is a neural 
correlate of fear memory (Quirk et al., 1995; Collins and Paré, 2000; Maren, 2000; Repa et al., 2001; Goosens et al., 2003), is modulated by context after extinction (Hobin et al., 2003). Interestingly, hippocampal inactivation impairs the context dependence of lateral amygdala neuronal activity evoked by extinguished CSs (Hobin and Maren, 2003). Hippocampal modulation of amygdala activity may be mediated via the prefrontal cortex, which is postulated to regulate neuronal excitability in the lateral and central amygdaloid nuclei after extinction (Rosenkranz and Grace, 2003; Paré et al., 2004). In this regard, the central role of the hippocampus in the neural circuit regulating the contextual control of extinction is important for understanding and treating clinical disorders of fear and anxiety in humans.

\section{References}

Benoit SC, Davidson TL, Chan K-H, Trigilio T, Jarrard LE (1999) Pavlovian conditioning and extinction of context cues and punctate CSs in rats with ibotenate lesions of the hippocampus. Psychobiology (Austin, Tex) 27:26-39.

Bouton ME (1993) Context, time, and memory retrieval in the interference paradigms of pavlovian conditioning. Psychol Bull 114:80-99.

Bouton ME (1994) Context, ambiguity, and classical conditioning. Curr Dir Psychol Sci 3:49-53.

Bouton ME, Bolles RC (1979) Contextual control of the extinction of conditioned fear. Learn Motiv 10:445-466.

Bouton ME, King DA (1983) Contextual control of the extinction of conditioned fear: tests for the associative value of the context. J Exp Psychol Anim Behav Process 9:248-265.

Bouton ME, Ricker ST (1994) Renewal of extinguished responding in a second context. Anim Learn Behav 22:317-324.

Bouton ME, Swartzentruber D (1986) Analysis of the associative and occasion-setting properties of contexts participating in a pavlovian discrimination. J Exp Psychol Anim Behav Process 12:333-350.

Brooks DC, Bouton ME (1993) A retrieval cue for extinction attenuates spontaneous recovery. J Exp Psychol Anim Behav Process 19:77-89.

Brooks DC, Bouton ME (1994) A retrieval cue for extinction attenuates response recovery (renewal) caused by a return to the conditioning context. J Exp Psychol Anim Behav Process 20:366-379.

Collins DR, Paré D (2000) Differential fear conditioning induces reciprocal changes in the sensory responses of lateral amygdala neurons to the CS $(+)$ and CS $(-)$. Learn Mem 7:97-103.

Corcoran KA, Maren S (2001) Hippocampal inactivation disrupts contextual retrieval of fear memory after extinction. J Neurosci 21:1720-1726.

Corcoran KA, Maren S (2004) Factors regulating the effects of hippocampal inactivation on renewal of conditional fear after extinction. Learn Mem 11:598-603.

Davis M (2002) Role of NMDA receptors and MAP kinase in the amygdala in extinction of fear: clinical implications for exposure therapy. Eur J Neurosci 16:395-398.

Davis M, Walker DL, Myers KM (2003) Role of the amygdala in fear extinction measured with potentiated startle. Ann NY Acad Sci 985:218-232.

Douglas RJ (1967) The hippocampus and behavior. Psychol Bull $67: 416-442$.

Edeline J-M, Hars B, Hennevin E, Cotillon N (2002) Muscimol diffusion after intracerebral microinjections: a reevaluation based on electrophysiological and autoradiographic quantifications. Neurobiol Learn Mem 78:100-124.

Fanselow MS (2000) Contextual fear, gestalt memories, and the hippocampus. Behav Brain Res 110:73-81.

Fischer A, Sananbenesi F, Schrick C, Spiess J, Radulovic J (2004) Distinct roles of hippocampal de novo protein synthesis and actin rearrangement in extinction of contextual fear. J Neurosci 24:1962-1966.

Frankland PW, Cestari V, Filipkowski RK, McDonald RJ, Silva AJ (1998) The dorsal hippocampus is essential for context discrimination but not for contextual conditioning. Behav Neurosci 112:863-874.

Freeman J, Cuppernell C, Flannery K, Gabriel M (1996) Context-specific multi-site cingulate cortical, limbic thalamic and hippocampal neuronal activity during concurrent discriminative approach and avoidance training in rabbits. J Neurosci 16:1538-1549.
Frohardt RJ, Guarraci FA, Bouton ME (2000) The effects of neurotoxic hippocampal lesions on two effects of context after extinction. Behav Neurosci 114:227-240.

Gabriel M (1993) Discriminative avoidance learning: a model system. In: Neurobiology of cingulate cortex and limbic thalamus (Gabriel M, Vogt B, eds), pp 478-523. Toronto: Birkhauser.

Good M, de Hoz L, Morris RG (1998) Contingent versus incidental context processing during conditioning: dissociation after excitiotoxic hippocampal plus dentate gyrus lesions. Hippocampus 8:147-159.

Goosens KA, Hobin JA, Maren S (2003) Auditory-evoked spike firing in the lateral amygdala and pavlovian fear conditioning: mnemonic code or fear bias? Neuron 40:1013-1022.

Hirsh R (1974) The hippocampus and contextual retrieval of information from memory: a theory. Behav Biol 12:421-444.

Hobin JA, Maren S (2003) Hippocampal inactivation eliminates the context-specific firing of lateral amygdala neurons after extinction. Soc Neurosci Abstr 29:199.9.

Hobin JA, Goosens KA, Maren S (2003) Context-dependent neuronal activity in the lateral amygdala represents fear memories after extinction. J Neurosci 23:8410-8416.

Holland PC, Lamoureux JA, Han J-S, Gallagher M (1999) Hippocampal lesions interfere with pavlovian negative occasion setting. Hippocampus 9:143-157.

Holt WG, Maren S (1999) Muscimol inactivation of the dorsal hippocampus impairs contextual retrieval of fear memory. J Neurosci 19:9054-9062.

Honey RC, Good M (1993) Selective hippocampal lesions abolish the contextual specificity of latent inhibition and conditioning. Behav Neurosci 107:23-33.

Ji J, Maren S (2005) Electrolytic lesions of the dorsal hippocampus disrupt renewal of conditional fear after extinction. Learn Mem 12:270-276.

Kennedy PJ, Shapiro ML (2004) Retrieving memories via internal context requires the hippocampus. J Neurosci 24:6979-6985.

Kim JJ, Fanselow MS (1992) Modality-specific retrograde amnesia of fear. Science 256:675-677.

Lattal M, Abel T (2001) Different requirements for protein synthesis in acquisition and extinction of spatial preferences and context-evoked fear. J Neurosci 21:5773-5780.

LeDoux JE, Iwata J, Pearl D, Reis DJ (1986) Disruption of auditory but not visual learning by destruction of intrinsic neurons in the rat medial geniculate body. Brain Res 371:395-399.

Mao J-B, Robinson JK (1998) Microinjection of GABA-A agonist muscimol into the dorsal but not the ventral hippocampus impairs non-mnemonic measures of delayed non-matching-to-position performance in rats. Brain Res 784:139-147.

Maren S (1998) Overtraining does not mitigate contextual fear conditioning deficits produced by neurotoxic lesions of the basolateral amygdala. J Neurosci 18:3088-3097.

Maren S (2000) Auditory fear conditioning increases CS-elicited spike firing in lateral amygdala neurons even after extensive overtraining. Eur J Neurosci 12:4047-4054.

Maren S, Fanselow MS (1997) Electrolytic lesions of the fimbria/fornix, dorsal hippocampus, or entorhinal cortex produce anterograde deficits in contextual fear conditioning in rats. Neurobiol Learn Mem 67:142-149.

Maren S, Holt W (2000) The hippocampus and contextual memory retrieval in pavlovian conditioning. Behav Brain Res 110:97-108.

Maren S, Quirk GJ (2004) Neuronal signalling of fear memory. Nat Rev Neurosci 5:844-852.

Maren S, Aharonov G, Fanselow MS (1997) Neurotoxic lesions of the dorsal hippocampus and pavlovian fear conditioning in rats. Behav Brain Res 88:261-274.

Martin JH (1991) Autoradiographic estimation of the extent of reversible inactivation produced by microinjection of lidocaine and muscimol in the rat. Neurosci Lett 127:160-164.

Martin JH, Ghez C (1999) Pharmacological inactivation in the analysis of the central control of movement. J Neurosci Methods 86:145-159.

Matus-Amat P, Higgins EA, Barrientos RM, Rudy JW (2004) The role of the dorsal hippocampus in the acquisition and retrieval of context memory representations. J Neurosci 24:2431-2439.

Milad MR, Quirk GJ (2002) Neurons in medial prefrontal cortex signal memory for fear extinction. Nature 420:70-74.

Mineka S, Mystkowski JL, Hladek D, Rodriguez BI (1999) The effects of 
changing contexts on return of fear following exposure therapy for spider fear. J Consult Clin Psychol 167:599-604.

Mystkowski JL, Craske MG, Echiverri AM (2002) Treatment context and return of fear in spider phobia. Behav Ther 33:399-416.

Pan HS, Frey KA, Young AB, Penney JB (1983) Changes in $\left[{ }^{3} \mathrm{H}\right]$ muscimol binding in substantia nigra, entopeduncular nucleus, globus pallidus, and thalamus after striatal lesions as demonstrated by quantitative receptor autoradiography. J Neurosci 3:1189-1198.

Paré D, Quirk GJ, LeDoux JE (2004) New vistas on amygdala networks in conditioned fear. J Neurophysiol 92:1-9.

Pavlov IP (1927) Conditioned reflexes. London: Oxford UP.

Phillips RG, LeDoux JE (1992) Differential contribution of amygdala and hippocampus to cued and contextual fear conditioning. Behav Neurosci 106:274-285.

Quirk GJ, Repa C, LeDoux JE (1995) Fear conditioning enhances shortlatency auditory responses of lateral amygdala neurons: parallel recordings in the freely behaving rat. Neuron 15:1029-1039.

Rauhut AS, Thomas BL, Ayers JJ (2001) Treatments that weaken pavlovian conditioned fear and thwart its renewal in rats: implications for treating human phobias. J Exp Psychol Anim Behav Process 27:99-114.

Repa JC, Muller J, Apergis J, Desrochers TM, Zhou Y, LeDoux JE (2001) Two different lateral amygdala cell populations contribute to the initiation and storage of memory. Nat Neurosci 4:724-731.

Riedel G, Micheau J, Lam AG, Roloff EL, Martin SJ, Bridge H, de Hoz L, Poeschel B, McCulloch J, Morris RGM (1999) Reversible neural inacti- vation reveals hippocampal participation in several memory processes. Nat Neurosci 2:898-905.

Rosenkranz JA, Grace AA (2003) Affective conditioning in the basolateral amygdala of anesthetized rats is modulated by dopamine and prefrontal cortical inputs. Ann NY Acad Sci 985:488-491.

Rudy JW, O’Reilly RC (1999) Contextual fear conditioning, conjunctive representations, pattern completion, and the hippocampus. Behav Neurosci 113:867-880.

Rudy JW, O’Reilly RC (2001) Conjunctive representations, the hippocampus, and contextual fear conditioning. Cogn Affect Behav Neurosci $1: 66-82$.

Santini E, Ge H, Ren K, Peña de Ortiz S, Quirk GJ (2004) Consolidation of fear extinction requires protein synthesis in the medial prefrontal cortex. J Neurosci 24:5704-5710.

Selden NR, Everitt BJ, Jarrard LE, Robbins TW (1991) Complementary roles for the amygdala and hippocampus in aversive conditioning to explicit and contextual cues. Neuroscience 42:335-350.

Smith D, Wakeman D, Patel J, Gabriel M (2004) Fornix lesions impair context-related cingulothalamic neuronal patterns and concurrent discrimination learning in rabbits (Oryctolagus cuniculus). Behav Neurosci 118:1225-1239.

Swanson LW (1992) Brain maps: structure of the rat brain. New York: Elsevier.

Wilson A, Brooks DC, Bouton ME (1995) The role of the rat hippocampal system in several effects of context in extinction. Behav Neurosci 109: $828-836$ 